\title{
Los valores éticos y la agenda del desarrollo: algunas consideraciones para la formación educativa
}

\author{
The ethical values and agenda of development: some considerations for \\ educational training \\ Valores éticos e agenda de desenvolvimento: algumas considerações para a \\ formação educacional \\ Oshiel Martínez Chapa \\ Universidad Autónoma de Tamaulipas, México \\ omartinez@uat.edu.mx \\ https://orcid.org/0000-0001-9675-5472
}

\section{Resumen}

En este trabajo se revisa una parte de la literatura existente respecto a la estrecha relación que guardan los valores éticos y la agenda del desarrollo en la perspectiva de la formación educativa, en este caso, la ciencia económica. El propósito es analizar la relevancia de estos fundamentos en la sociedad actual en virtud de las demandas de acciones favorables para reducir las desigualdades y mejorar las condiciones de vida material. Para ello, se utilizó una metodología cualitativa consistente en el estudio de documentos y la consecuente reflexión al respecto. El tema es significativo justo ahora en que se plantea si las instituciones de educación superior (IES) coadyuvan a la enseñanza de los valores para el ejercicio profesional. El trabajo muestra que, en general, los profesionales de la economía han subestimado el carácter pertinente de la ética en la agenda del desarrollo, de lo cual se ha advertido desde hace un tiempo considerable. En el trabajo se concluye la necesidad de impulsar los valores éticos como medios que posibilitan un desarrollo social y económico menos desigual.

Palabras clave: desarrollo social y económico, educación, judeocristianismo, planes de estudio, responsabilidad social y ética, valores éticos. 


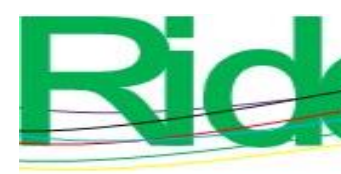
Revista Iberoamericana para la
Investigación y el Desarrollo Educativo
ISSN $2007-7467$

\section{Abstract}

This paper reviews a part of the existing literature regarding the close relationship between ethical values and the development agenda in the perspective of educational training, in this case, economics. The fundamental purpose of this research is to analyze the relevance of these foundations today by virtue of the demands for actions in favor of reducing inequalities and improving material living conditions. A qualitative methodology consisting of the study of documents and the consequent reflection on the matter was used. The issue is significant right now when it arises whether higher education educational institutions (IES) contribute to the teaching of values for professional practice. The work shows that economics professionals have generally underestimated the relevance of ethics on the development agenda, and this has long been warned about. The work concludes on the need to promote ethical values as means that enable less unequal social and economic development.

Keywords: social and economic development, education, Judeo-Christianity, curricula, social and ethical responsibility, ethics values.

\section{Resumo}

Este artigo revisa parte da literatura existente a respeito da estreita relação entre os valores éticos e a agenda do desenvolvimento na perspectiva da formação educacional, no caso, a economia. O objetivo é analisar a relevância dessas bases na sociedade atual em função das demandas por ações favoráveis para reduzir as desigualdades e melhorar as condições materiais de vida. Para tanto, utilizou-se uma metodologia qualitativa que consiste no estudo de documentos e a consequente reflexão sobre o assunto. A questão é significativa agora, quando surge a questão de saber se as instituições de ensino superior (IES) contribuem para o ensino de valores para a prática profissional. O trabalho mostra que, em geral, os profissionais da economia têm subestimado a relevância da ética na agenda do desenvolvimento, o que há muito vem sendo alertado. $\mathrm{O}$ trabalho conclui a necessidade de

promover os valores éticos como meios que possibilitem um desenvolvimento social e econômico menos desigual.

Palavras-chave: desenvolvimento social e econômico, educação, judaico-cristianismo, planos de estudos, responsabilidade social e ética, valores éticos. 


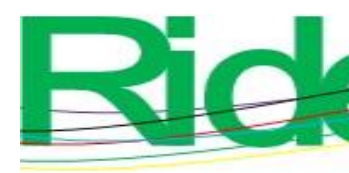

Fecha Recepción: Octubre 2020
Revista Iberoamericana para la

Investigación y el Desarrollo Educativo

ISSN $2007-7467$

Fecha Aceptación: Marzo 2021

\section{Introducción}

El tema de los valores éticos cobra dimensión justo ahora cuando crece la preocupación por temas diversos como derechos humanos, democracia, desarrollo sustentable, participación ciudadana, transparencia, rendición de cuentas, lucha contra la corrupción y el crimen, etc. Esta temática se ha incorporado en la agenda de la mayoría de las organizaciones económicas, políticas y sociales de los países. Es evidente que los valores nunca pierden vigencia ni relevancia porque, en buena medida, reflejan nuestra conducta. Su abordaje resulta crucial, pues en diversas naciones del mundo se advierten rasgos preocupantes de fractura social debido a la descomposición moral, principalmente. La familia, el Estado y el resto de las instituciones públicas y privadas evidencian una agudización de la crisis de los valores referidos.

El presente esfuerzo constituye un acercamiento al mundo de las profesiones, aunque en este caso se considera una parte del contenido del plan de estudios de la licenciatura en Economía. No obstante, no puede limitarse su alcance a dicha profesión, pues los valores éticos tienen un alance universal. El presente artículo, por tanto, se estructura de la siguiente forma: en la primera parte se señala una introducción al tema en cuestión, en el segundo apartado se aborda la metodología empleada — en este caso, de tipo cualitativa—, la tercera parte se enfoca en la discusión y, finalmente, se exponen las consideraciones finales.

Según la Real Academia Española (2020), la palabra ética se refiere al "conjunto de normas morales que rigen la conducta de la persona en cualquier ámbito de la vida". Por su parte, el Diccionario Word Reference (2020) la relaciona con la conducta, la moral, la norma, el comportamiento y la deontología. Para Martínez Navarro (2017), la ética es parte de la filosofía que trata del bien y del fundamento de sus valores. En este mismo orden de ideas, debe señalarse que los valores están orientados hacia el bien de los demás. Se trata también de ideas, ideales, creencias y convicciones enseñados desde el hogar y desde la perspectiva la religión judeocristiana. En el mejor de los casos, los valores promue ven las potencialidades de las personas, como la rectitud, la lealtad, la responsabilidad, el respeto, la cooperación, la justicia, la armonía, entre otros. 


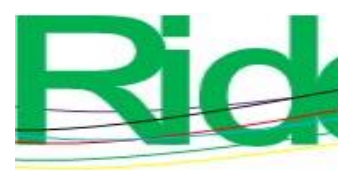

Revista Iberoamericana para la Investigación y el Desarrollo Educativo ISSN $2007-7467$

Los valores éticos tienen significado en la perspectiva del desarrollo económico y social; el no tener buenos referentes impacta adversamente a las naciones en su conjunto. Al respecto, Klicksberg (2006) sostiene lo siguiente:

Hay una sed de ética en América Latina. La opinión pública reclama en las encuestas y por todos los canales posibles comportamientos éticos en los líderes de todas las áreas y temas cruciales como el diseño de las políticas económicas y sociales y la asignación de recursos sean orientados por criterios éticos. Contrariamente a ese sentir, las visiones económicas predominantes en la región tienden a desvincular ética y economía. Sugieren que son dos mundos diferentes con sus propias leyes, y que la ética es un tema para el reino del espíritu. Este tipo de concepción que margina los valores morales parece haber sido una de las causas centrales del "vacío ético" en el que se han precipitado varias sociedades latinoamericanas. La idea de que los valores no importan mayormente en la vía económica práctica ha facilitado la instalación de prácticas corruptas que han causado enormes daños (p. 2).

Con base en la idea anterior, a continuación se revisan algunos trabajos ubicados en esta línea del conocimiento. Destaca, en primer término, la indagación de Racko (2017), quien explica que la enseñanza de la economía como disciplina se asocia con un incremento del hedonismo, los valores que sustentan el poder económico, así como la reducción de los valores de autodirección y otros universalmente aceptados. El autor en cuestión asevera que la enseñanza de esta disciplina aborda aspectos tales como valores, costos (de oportunidad), maximización de utilidad, racionalidad, eficiencia, posibilidades de expansión y demás valores de una ciencia normativa, la cual descansa en el mismo positivismo. En este contexto, el estudio de la economía pretende aplicar los supuestos de una ciencia natural, la cual no entraña valoraciones de tipo ético.

Otro trabajo que merece señalarse es el de Brant (2011), quien sugiere repensar la enseñanza de esta disciplina, pues cada vez más un mayor número de estudiantes, maestros y demás ciudadanos exigen una explicación respecto a las diversas crisis que afectan la vida de millones de personas. Se demanda una justificación sobre los hechos de la prevalencia de la desigualdad social, especulación, concentración de la riqueza y demás desafíos económicos y de tipo político y ético. 


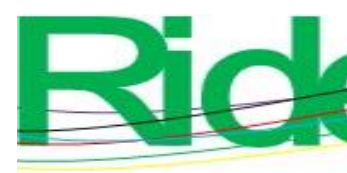

Revista Iberoamericana para la
Investigación y el Desarrollo Educativo
ISSN $2007-7467$

De acuerdo con Latapí (1999), las crisis de los países son más que crisis meramente de carácter social y económico: su dimensión ética es mayúscula y por demás seria. Ante todo, se tiene una falla grave en las valoraciones, actitudes y formas de relaciones, pues no puede haber convivencia ordenada sin la vigencia de los valores comunes, aceptados y respetados, ni moral pública efectiva que no se articule en las conciencias individuales.

Con respecto a esta condición de crisis de valoraciones, Florencio Contreras (2009) sostiene lo siguiente:

De modo que lo que está ocurriendo no es una serie de contratiempos aislados, sino un auténtico fracaso sistémico, del que por cierto ya nos habíamos dado cuenta no hace poco tiempo, cuando empezamos a ver qué instituciones nucleares como la familia, las escuelas, los sistemas de salud y de impartición de justicia, las empresas y otras empezaron a tambalearse y a romperse, agobiadas por problemas de deslealtad, falta de responsabilidad y respeto, corrupción, fraudes y un sinfín de cuestiones que reflejan no solo la decadencia o la quiebra de la estructura institucional, sino la agonía de una cultura, el sistema de valores y el carácter social de un sistema de riqueza anterior (Florencio Contreras, 2009, pp. 32-33).

Según Sen (2002), la capacidad real que tiene una persona para alcanzar logros está bajo la influencia de las oportunidades económicas, las libertades políticas, las facilidades sociales y las condiciones habilitantes de buena salud, educación básica, así como el aliento y cultivo de iniciativas. Estas oportunidades son en gran parte complementarias y tienden a reforzarse en su alcance y utilidad respectivos. Por estas interconexiones el ente libre y sostenible emerge como un medio de desarrollo efectivo. No es posible ser pragmático o indiferente a la necesidad de respetar los principios éticos y legales fundamentales en la norma de la conducta.

En este orden de ideas, y de acuerdo con Ortega y Gasset (1973), estamos viviendo actitudes de individualismo y una nueva forma de despotismo. Ahora mismo nos encontramos en un mundo de aislamiento y de pérdida del interés por los demás o por la sociedad, y ello está ocurriendo a pesar de las muestras de solidaridad ante desastres naturales o conflictos bélicos. Para el referido autor, las personas y las naciones ya se encontraban en una condición de enajenamiento y a merced de los intereses del mercado, sin otra utilidad que la de engrosar los beneficios de sociedades sin rostro. 


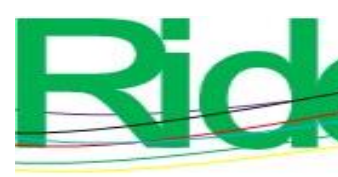

Revista Iberoamericana para la Investigación y el Desarrollo Educativo ISSN $2007-7467$

Sin embargo, conviene plantear la siguiente pregunta: ¿por qué se han debilitado las instituciones encargadas de la equidad y el desarrollo tales como el Estado, especialmente en las naciones pobres? Debe reconocerse que, aunada a la debilidad estructural de la economía, también se halla la propia fragilidad institucional. El llamado Estado de derecho — tan invocado frecuentemente por los líderes de estas naciones - suele transgredirse; una muestra de ello son problemáticas complejas y crecientes como el deterioro ambiental, las bajas remuneraciones, el desempleo, la criminalidad y la desesperanza social.

Los valores tienen un carácter universal y trascienden el aula escolar. En términos generales, debe hablarse de valores que son afines en las profesiones, artes y todo el quehacer de las personas. Los fracasos educativos derivan del fracaso de la parte social y económica, y la ética debe ofrecer una respuesta a ello. Las crisis ocurridas en el seno de las familias y de las organizaciones son un fiel reflejo de las crisis explicadas en la misma ética, ya sea en lo individual como en lo colectivo. En el plano de los países deben indicarse como señales claras de crisis de valores a la creciente inseguridad pública, convertida en una amenaza para sus respectivas soberanías y desafíos al estado de derecho. De acuerdo con Ramos Sánchez (2010), aunado a ello, hay muestras de agotamiento de las instituciones de procuración de justicia, de ausencia de negociación pacífica con respecto a las diferencias políticas y de un papel muy cuestionado del Estado en su tarea de favorecer una sociedad menos desigual y dividida.

Es igualmente lamentable que la economía se organice para mantener el estado de las cosas casi inalterable, y con ello se afecte el destino de las grandes mayorías, las cuales no avizoran un derrotero más prometedor en el corto plazo. Es una pena que no se le ponga freno al lucro desmedido y que los estándares de competitividad empresarial, en muchos casos, entrañen la explotación de recursos humanos y naturales por igual. Estas condiciones de desigualdad empujan a millones de personas en el mundo a abandonar familia y país con la esperanza de superar sus serias desventajas en otras naciones.

Por otro lado, debe señalarse que una considerable parte de los ciudadanos se identifican con valores como la solidaridad, justicia, inclusión, igualdad de oportunidades, entre otros. No obstante, existe una paradoja, pues persisten patrones de conductas que reflejan en buena medida lo contrario. Entre otros, las principales contradicciones se relacionan con aspectos como los siguientes: 


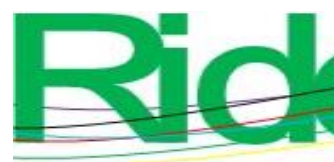

Revista Iberoamericana para la
Investigación y el Desarrollo Educativo
ISSN $2007-7467$

- En general, existe un limitado sentido de solidaridad con los ciudadanos en desventaja, pobres, desempleados, víctimas de desgracias naturales y con aquellos que sufren discriminación y de prejuicios sociales.

- En la actualidad, suelen valorarse más los bienes extranjeros que los nacionales, aunque ello implique menos puestos de trabajo con contenido local, así como falta de oportunidades para potenciar las economías de las regiones más necesitadas de apoyo.

- En las últimas décadas se ha acentuado la migración rural-urbana y la inmigración es una realidad que contrasta con las promesas gubernamentales de desarrollo, pero que impulsaron la apertura comercial y la globalización con las implicaciones adversas para la mayoría de los productores agropecuarios.

- El empleo rural y urbano se halla en franca crisis y cada vez se vuelve más complicada su generación formal.

- La evasión fiscal y la desconfianza ciudadana con respecto a las instituciones y a los funcionarios es muy elevada.

- Existe evidencia de falta de respeto hacia el orden y la legalidad. La policía y el ejército son desafiados por la creciente ola de criminalidad y violencia que se vive en muchos países. El contrabando, la piratería y todas las actividades de la delincuencia organizada son enormemente lucrativas y se tiene en la impunidad, capacidad de infiltración y fragilidad estructural del sistema político y judicial, oportunidades para su prevalencia.

- Una indeterminada cantidad de ciudadanos no se siente representado políticamente y cree que las autoridades tienen una agenda política y económica que deja de lado la atención de las demandas urgentes de las mismas mayorías.

- No son pocos los que consideran que la búsqueda de puestos políticos se halla motivada fundamentalmente por razones egoístas, más que por el interés de servicio a la sociedad.

Al tener en cuenta los fundamentos éticos y legales se privilegian acciones como la cooperación, armonía, respeto por la soberanía nacional, solidaridad, entre otros. Con esto último, seguramente los niveles de pobreza y exclusión serían casi inexistentes. Las naciones que privilegian estos principios constituyen una elocuente realidad que por sí mismas confirman que la justicia ciertamente les engrandece (Proverbios 14: 34, versión Reina Valera, 1960). 

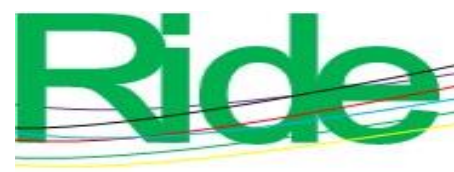

Revista Iberoamericana para la Investigación y el Desarrollo Educativo ISSN 2007 - 7467

Los valores inspirados en el judeocristianismo no solo son privativos de Israel como nación: ellos se encuentran escritos para todas las generaciones. Según Leibowitz (1995), en el mandato divino la pobreza debe ser erradicada, y ello no solo debe entenderse como una promesa divina, sino como una exigencia impuesta al hombre. De acuerdo con el autor, se debe evitar crear una realidad en la que habrá indigencia.

Los valores son elementos espirituales que nutren la vida del individuo. La cultura, el derecho y las mismas instituciones lo reconocen y sus prácticas están orientadas por naturaleza a la consecución de aquellos. Destacan el amor, la pureza, la esperanza, la justicia, la bondad, etc. La educación está obligada a reforzar y transmitir dichos valores universalmente conocidos.

Como hipótesis debe señalarse la necesidad de que las instituciones educativas adopten un papel más activo en la enseñanza de los valores éticos a fin de que los futuros profesionistas desempeñen sus competencias en entornos donde a menudo enfrentan dilemas éticos. Este tipo de acciones no excluyen la responsabilidad de los padres de familia, organizaciones religiosas y demás instituciones. Ante la agenda de desarrollo se precisa levantar la voz de exigencia de una orientación hacia los valores como medios para reducir las desigualdades sociales y traer bienestar.

\section{Metodología}

Este trabajo se basó en el método cualitativo para analizar 1) las consideraciones respecto a las implicaciones de los valores en los contenidos seleccionados de un plan de estudios de una licenciatura en Economía, 2) las consideraciones respecto a los valores que promueven las instituciones de educación superior (IES), y 3) las consideraciones respecto a los retos del desarrollo. 


\section{Consideraciones respecto a las implicaciones de los valores en los contenidos seleccionados de los estudios de una licenciatura en Economía}

\section{(LE)}

La misión institucional del plan de estudio de la licenciatura en Economía seleccionada para este trabajo se puede definir en términos de la preparación de profesionistas dedicados al estudio de las formas en las que la sociedad utiliza los recursos limitados para transformarlos en satisfactores, así como la contribución de estos al bienestar general. En dicho plan se hace hincapié en formar profesionistas dentro de las especialidades que se imparten, ofreciendo las apropiadas condiciones para su formación.

Debe destacarse que las organizaciones modernas están experimentando grandes transformaciones en su diario vivir, para lo cual deben preparar al profesional en un entorno caracterizado por factores como la fuerte competencia, la innovación técnica continua, las regulaciones y la apertura al comercio mundial. En ese sentido, el futuro profesionista tiene el reto de ser proactivo frente a las condiciones complejas del presente. Se espera, adicionalmente, que sea sensible a las problemáticas de carácter económico, tales como la pobreza y las desigualdades, así como en lo social y ambiental, toda vez que se experimenta un notable deterioro en el medio ambiente, ello como un reflejo de la crisis actual de valores.

En este esfuerzo de análisis de los contenidos e implicaciones de los valores se han seleccionado algunos temas de cuatro materias (a manera de muestra): Macroeconomía, Administración, Medio Ambiente y Desarrollo Sustentable, así como Microeconomía. A continuación, se describe cada una de ellas.

En el curso de Macroeconomía — como en otros de disciplinas sociales— los autores de los textos y publicaciones científicas parten de la premisa teórica de la neutralidad de las conductas humanas. Por ejemplo, se cree comúnmente que el ciclo económico es un fenómeno natural y aun predecible. Sin embargo, el hecho es que las crisis económicas asociadas al desempleo, pobreza, exclusión social, déficit público, devaluación, inflación y demás problemas tienen una explicación en la falta de supervisión y de apego a las regulaciones e instituciones creadas. Más allá de todo esto, se encuentran las personas y las relaciones que guardan entre sí. Cabe señalar que conductas de avaricia y corrupción traen como resultado escasez, especulación, desigualdad social y demás adversidades, pues se dejan fuera del alcance de las mayorías los satisfactores esenciales. Asimismo, deben señalarse los roles que juegan los aspectos como el emprendimiento, la innovación, la libertad 


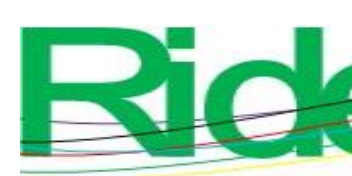

Revista Iberoamericana para la Investigación y el Desarrollo Educativo ISSN 2007 - 7467

de emprender y la acción pública en favor de la creación de empresas y empleos. Por tanto, “dejar hacer, dejar pasar” no tiene el mismo significado en Nigeria que en Noruega.

En el curso de Administración se incorporan, entre otros, los contenidos de la responsabilidad social y ética de las organizaciones (RSE). Las normas y principios creados tienen por objeto definir límites en favor de la libre competencia, libertad de elección y defensa legal de los ciudadanos. A pesar de la existencia de dichas regulaciones e instituciones, el hecho es que cuando las corporaciones tienden a concentrar enorme poder económico — y político—, el ciudadano ordinario queda en un estado de indefensión ante las prácticas depredadoras de aquellas. No obstante, cuando el Estado es fuerte y hace valer las leyes, los ciudadanos y los demás agentes económicos y sociales son respetados en sus derechos esenciales. No en vano en los países de alto nivel de bienestar, la RSE guarda estrecha correspondencia con el desarrollo social y económico.

El asunto es que las organizaciones en general perciben las metas de RSE como solo una lista de valores importantes y donde la consecución de estos se halla sujeta a la buena voluntad de los miembros participantes: directivos, empleados y demás grupos de interés. Se plantea la necesidad del involucramiento sin forzar o exigir a nadie, pues quien no apoye no corre el riesgo de ser sancionado. Su virtud consiste en involucrar a la acción comprometida, especialmente con aquellos ciudadanos que tienen necesidad de apoyos debido a sus bajos ingresos y carencias.

Por su parte, en el curso de Medio Ambiente y Desarrollo Sustentable se contempla una revisión de los aspectos relativos a la protección del medio ambiente, especialmente en lo que se relaciona con sus problemáticas, regulaciones y desafíos respecto al futuro. Se estudian los roles propios de los gobiernos, las empresas, los consumidores y los demás agentes económicos, sociales y políticos. Una línea de estudio consiste en el análisis del deterioro ambiental de las regiones, para pasar a otra en la que ha de analizarse la dimensión de intervención sobre el cuidado del medio ambiente, como pueden ser la legal, la conservacionista, la del desarrollo sustentable y la de la ética normativa, fundamentalmente. Debe, por tanto, puntualizarse que la forma en que se está produciendo y consumiendo en la actualidad compromete seriamente los recursos naturales, por lo que las generaciones futuras encaran un reto mayor, pues a la vista se encuentran problemáticas más complejas que las actuales. Aquí son fundamentales las acciones legales, la supervisión y el sentido de respeto 


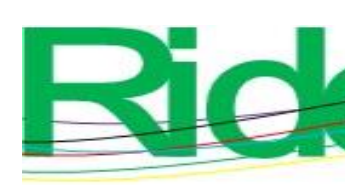

Revista Iberoamericana para la Investigación y el Desarrollo Educativo ISSN $2007-7467$

por los recursos naturales, sin descuidar los aspectos científicos y tecnológicos, desde una perspectiva de los valores.

En la actualidad se hace hincapié en los aspectos del desarrollo sustentable en cuanto a propuestas de empleo, crecimiento económico, uso de energías renovables, aprovechamiento de recursos naturales, consumo responsable, economía colaborativa y subsidiaria, etc. Esta nueva visión representa un enfoque alternativo, iniciado y desarrollado en naciones con mayores niveles de bienestar social. En países como México, los estudiantes y maestros requieren de mayores apoyos económicos para hacer realidad todo lo que se propone en los planes de estudio en lo concerniente a la mejora de la calidad y preparación académica. Lo anterior es tan deseable como plausible; sin embargo, se requiere en muchos casos de manera urgente la dotación de la infraestructura humana, técnica y financiera adecuada para implementar este tipo de propuestas.

En el curso de Microeconomía se abordan, entre otros temas, el de la estructura de mercado, dentro de la cual se estudia a la competencia perfecta e imperfecta. En este curso se planea cómo es que la conducta de las grandes empresas — competencia imperfecta— tiende hacia la concentración del mercado, para lo cual implementan estrategias caracterizadas por el control de la producción, competencia ajena al precio, diferenciación e innovación constante, prácticas de fijación de precios y beneficios extraordinarios, etc. Estas corporaciones lo llevan a cabo aun cuando no siempre prevalezcan criterios como la competencia justa, satisfacción del mercado, producción sin externalidades y demás aspectos.

Debe señalarse que frente a gobiernos débiles y ciudadanos indefensos, las corporaciones empresariales suelen actuar de forma contraria al interés público. En el peor de los casos, se advierten prácticas de corrupción, fraude y, lo más grave, impunidad. Por otro lado, cabe señalar la innegable contribución que tienen las empresas en el desarrollo económico, especialmente en términos de beneficios como el empleo, la contribución fiscal, la generación de empleos, la producción de bienes y demás. En ese sentido, es de esperar su compromiso con seriedad. 


\section{Consideraciones respecto a los valores que promueven las instituciones de educación superior (IES)}

Entre otros, los valores que se invocan en los planes de estudios de la LE —esencialmente en todas las profesiones_ son la pulcritud, la disciplina y el respeto a los reglamentos y estatutos. Se hace énfasis en la eficiencia y la calidad de los procesos y productos. Se pretende, adicionalmente, que el estudiante desarrolle rasgos como ser innovador, creativo, propositivo, emprendedor, con sentido de responsabilidad, orgullo por la profesión, fomento al bienestar, así como ética profesional y los demás valores universales.

Las asignaturas del programa académico señalado más idóneas para reforzar los valores, aunque no son las únicas, son Ética, Filosofía, Desarrollo Sustentable, Desarrollo Económico, Economía Política, Historia, entre otros, aunque todas las asignaturas deberían contenerlos de forma implícita. El principal motivo tiene que ver con la formación integral de valores a fin de prepararse para vivir en sociedad. Puede establecerse que desde los niveles de educación básica se enseña este tipo de contenidos, los cuales se van reforzando en otros niveles.

Por otro lado, en los planes de estudio de la LE, en general, se reconoce la complejidad de la dinámica social y económica. Ahora el enfoque de la preparación académica incorpora elementos tales como los estudios de la globalización, tecnología y computación, e idiomas obligatorios, por mencionar algunos. No obstante, hace falta incorporar con mayor fuerza la perspectiva de lo local, regional o comunitario como campos de acción a fin de influir favorablemente en el entorno del estudiante y futuro profesionista.

Asimismo, en el sistema educativo mexicano generalmente se enfatiza más en la competencia que en la cooperación. Se privilegia más el individualismo que las formas de asociación, lo cual tiene que ver con una cultura de falta de confianza y de trabajo aislado. Son, por tanto, indispensables los sistemas de enseñanza y evaluación basados en el trabajo colaborativo y con un enfoque de involucramiento social, especialmente con las comunidades que viven en rezago y con desventaja.

Por otro lado, en lo que respecta a los programas de valores institucionales de la IES, debe subrayarse su carácter indispensable de vincularse con la sociedad a la cual se debe. Existen presiones para incorporar y hacer valer los principios de responsabilidad social y ética (RSE) ante los retos del desarrollo. Los valores institucionales se circunscriben al ámbito del deber ser, es decir, del ideal normativo que debiera modelar a dichas instituciones 


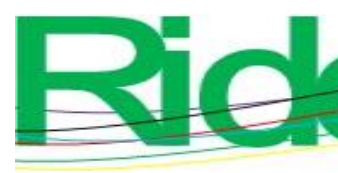

Revista Iberoamericana para la Investigación y el Desarrollo Educativo ISSN $2007-7467$

y que están llamadas a corresponder con la sociedad en general y a las comunidades en particular, puesto que de ambas se sirve en cuanto a recursos humanos, financieros y científicos.

Las instituciones educativas públicas o privadas deben mantener una imagen favorable con todo el público posible. Los programas de RSE están ideados para cubrir necesidades de carácter material y de corto plazo. No pueden trascender en la formación espiritual de los individuos, aun cuando lo desearan. Las motivaciones subyacentes no deben importar para quienes tienen un propósito de solidaridad sin publicidad o autocomplacencia.

\section{Consideraciones respecto a los retos del desarrollo}

Los estudiantes y los profesionales de la ciencia económica se hallan familiarizados con los temas del desarrollo, pues estos se abordan durante su formación, pero además exigen valoraciones sociales desde una perspectiva ética y legal. La denominada "ley del más fuerte" suele imponerse en sociedades estructuralmente frágiles en sus instituciones. El resultado es la desconfianza, la frustración social y aun la misma crispación. Por ello, no en pocos países los procesos electorales se suelen cuestionar. Las crisis de las naciones son el resultado de las crisis de sus ciudadanos. En ese sentido, es válido preguntarse en qué nos ayudan los valores. Ellos nos previenen de las grandes tragedias que hunden a las mismas civilizaciones en la ignominia. El apegarnos a los valores universales da sentido y certidumbre, pues nos acercan de tal modo que podemos identificar nuestros problemas y buscarles soluciones.

La promoción del desarrollo que solo privilegia la perspectiva materialista desecha las realidades espirituales y éticas que son necesarias para tener un planteamiento global de los problemas; el hombre tiene necesidades, pero también es un ser trascendente que necesita respuestas espirituales a fin de desarrollar su ética. Las concepciones de autosuficiencia y de desprecio por los valores espirituales lo llevan a eludir el problema raíz de la existencia del mal que identifica la teología y, por tanto, la necesidad de redención.

Respecto a la crisis de valores imperantes y, por tanto, del mismo desarrollo, A. W. Tozer (2013) destaca el hecho de cómo es que desde hace siglos a cada generación joven sus maestros le han enseñado que el mundo va a mejorar. Se ha creído que, de la mano de la ciencia y de la técnica, la humanidad gradualmente tomará la senda del progreso para llegar al umbral en el cual no habrá más injusticia, ni pobreza, ni desigualdad. Según esta óptica, la 


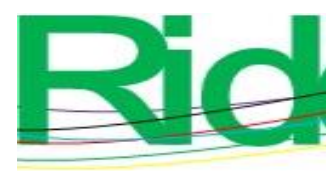

Revista Iberoamericana para la
Investigación y el Desarrollo Educativo
ISSN $2007-7467$

educación y la ética ayudarán a superar nuestros problemas. Al respecto, el autor sostiene lo siguiente:

Vivimos en un tiempo de asombrosas maravillas electrónicas y tecnológicas. De luz artificial en vez de velas, de transportación supersónica en vez de carros tirados por bueyes. Instantáneas comunicaciones mundiales en vez de correos a pie o a caballo. Nuestros maestros han llegado a la conclusión de que debemos estar mejor porque conocemos mucho más. Sin embargo, nuestro avance científico e intelectual no ha ido acompañado de un progreso moral equivalente. Al mismo tiempo que nuestros sueños fabricados de juguetes se hacían realidad, en muchos de estos mismos lugares, aparecían los más terribles y espantosos, increíblemente crueles y malvados estados de cosas, desde los tiempos de Noé. Hemos sabido de cámaras de gas, masacres, campos de concentración, muertes masivas de hambre, brutalidades, marchas de la muerte, y mucho de este profundo desprecio por la vida humana ha tenido lugar exactamente en las mismas áreas donde nuestros avances científicos eran cultivados. La tecnología en vez de hacernos moralmente mejores ha ido acompañada de un tiempo de desintegración moral (Tozer, 2013, p. 68).

Desde la posguerra, a mediados del siglo XX, el destino de un contingente de naciones se ha venido ligando cada vez más a incrementar la calidad de vida de su población. Los niveles de salud, educación, cultura y participación ciudadanas son decisivos para la existencia de democracias estables, desarrollo sostenido, así como la preservación del medio ambiente. Los países que han invertido más en el capital humano y social de modo sostenido lo han hecho con la visión de privilegiar el progreso y a la vez reducir las disparidades sociales. 


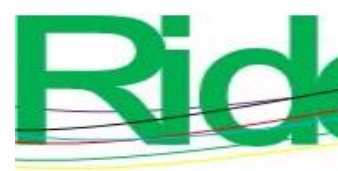

Revista Iberoamericana para la Investigación y el Desarrollo Educativo ISSN 2007-7467

\section{Discusión}

La perspectiva del desarrollo humanista se queda corta, pues coloca al hombre en el centro del mundo. Esta perspectiva ha reaparecido y cobrado una fuerza muy importante gracias a los informes de desarrollo humano publicados por el Programa de Naciones Unidas para el Desarrollo (2019) a principios de los años 90. Desde entonces, los expertos de la pobreza diseñaron indicadores como el Índice de Desarrollo Humano (IDH), el cual está compuesto por tres componentes básicos: longevidad, escolaridad y capacidad económica, y muestra que, aunque las economías de los países se coloquen en los primeros lugares de la tabla mundial, su desempeño en términos de desarrollo humano puede variar considerablemente. Sin embargo, existen otros aspectos que se dejan de lado aun cuando se pueda observar progreso material. La crisis de identidad, soledad, vacío existencial y demás conductas similares revelan que ciertamente "no solo de pan vivirá el hombre" (San Mateo $4: 4)$.

El desarrollo y el crecimiento económico constituyen medios fundamentales para la promoción del bienestar. Cada sociedad decide qué aspectos considerar en su respectiva visión de estos. Puede ser más o menos propensa a medir el bienestar en términos de orden material o no. Sin embargo, una gran parte de la humanidad está sufriendo carencias elementales de manera persistente a pesar de la creación de instituciones internacionales comprometidas con las agendas para reducir las brechas sociales (Acemoğlu y Robinson, 2012). Aún más, se hallan pendientes asuntos indispensables en aras de mejorar la distribución de la riqueza y el acceso a condiciones fundamentales de vida digna. Respecto a estos retos, Altman (2002) puntualiza aspectos de gran relevancia que revisten la atención urgente:

Ante el fenómeno del creciente desbalance económico y social a nivel internacional y a nivel interno de muchos países, parece crecer el reconocimiento, también en organismos financieros internacionales, de que el mercado, aun teniendo leyes propias, necesita también del control del Estado y que el debilitamiento de los estados es parte de las causas de la pobreza. La premisa de esa aserción parece ser el reconocimiento de que el mercado por sí solo no resulta en mayor equidad social y que el Estado, por ser representativo de la población, estaría más propenso a garantizar esa calidad del desarrollo económico. Aun así, tampoco el Estado como institución puede 


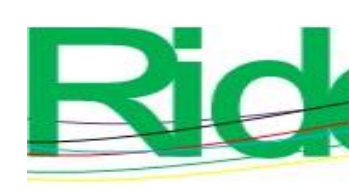

Revista Iberoamericana para la
Investigación y el Desarrollo Educativo
ISSN $2007-7467$

por sí solo proporcionar la calidad social de las relaciones económicas, pues no hay ninguna garantía previa de que el Estado sea un instrumento de la voluntad comunitaria de los pueblos, y no un instrumento de los mismos intereses económicos particulares imperantes en el mercado (Altman, 2002, p. 183).

Un aspecto adicional que merece comentarse en este apartado tiene que ver con el hecho de que una gran parte de la humanidad por siglos ha tenido recursos esenciales; unas naciones más de cierto(s) recurso(s) que de otros, pero en general pueden fincar su desarrollo en condiciones suficientes. De existir cooperación, armonía y comercio justo, el mundo no experimentaría la gravedad de tales contradicciones. Lo que algunos tienen en abundancia lo pueden comerciar para obtener lo que les hace falta de otros en términos de mayor justicia distributiva, es decir, que los precios y salarios también contemplen la necesidad y la dignidad humanas.

En un mundo de mayor cooperación y justicia distributiva no habría lugar para las hambrunas, epidemias, guerras y demás calamidades, las cuales se han querido desterrar para siempre desde hace siglos. Sin embargo, ante la codicia y el desenfreno del consumo, derroche de recursos y energías, lo que tenemos es un deterioro en las condiciones de vida material y ambiental de una gran parte de la humanidad.

Existe una fuerte interconexión entre los valores éticos y el desarrollo. En ese sentido, la educación es importante por más razones que las simples y comunes. No solamente nos proporciona conocimientos, más bien debe ayudarnos a trascender y a la vez relacionarnos a fin de comprender mejor del mundo en el que vivimos. Debe, asimismo, hacernos consientes de los retos presentes a fin de prepararnos para resolverlos con inteligencia y determinación. La educación es la ventana por la cual vemos al mundo y es deseable que sea más amplia. Debe ser el puente para una vida mejor en aspectos tan fundamentales como la prolongación de la vida, la realización de un mejor trabajo, la erradicación del hambre, la pobreza y la misma guerra. La educación con valores es tarea de todos, pero estará limitada si se asume que es solo privativa de instituciones educativas.

Los valores y el desarrollo económico deben contribuir a cambiar el estado de cosas en aquellos países que sufren desesperadamente por el abandono y la indiferencia de sus propios compatriotas. Las mismas destrezas y habilidades humanas son un activo potencial de todas las culturas; desarrollarlas al máximo debe ser un compromiso de la generación 


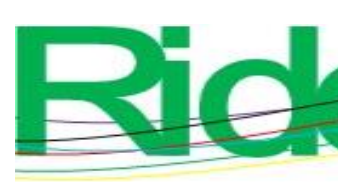

Revista Iberoamericana para la
Investigación y el Desarrollo Educativo
ISSN $2007-7467$

actual en beneficio de las próximas. La educación y, en general, el capital humano deben cambiar la marginación, pobreza, ignorancia y demás en oportunidades de una vida más digna y valiosa. Las personas nos relacionamos y debemos considerar imperativa la atención a los más desfavorecidos, dado que no satisfacen sus necesidades básicas.

Para la promoción del desarrollo los estados nacionales deben asegurarse la aplicación de recursos al presupuesto de gasto. Las empresas y los demás agentes económicos de la sociedad deben contribuir a dicho propósito. De acuerdo con Bernardo (1993), los estados nacionales tradicionalmente han recurrido a una serie de instrumentos de política del bien común, dentro de los cuales se destacan los impuestos y los cargos públicos. El citado autor también explica que en cuanto a los impuestos, la ley es el medio más importante del que dispone un gobierno para realizar el bien común. Podemos afirmar que la ley es válida en la medida en que es un instrumento del bienestar general.

En una política del bien común, los gobernantes deben esforzarse por dar un sentido social al impuesto, lo cual se relaciona con 1) la justa distribución de las cargas para que todos paguen según sus posibilidades y la condición de cada uno; 2) el problema del impuesto es más bien un problema de gastos, y 3) castigar los abusos en el empleo de fondos públicos; al respecto, los ciudadanos tienen el derecho de exigir responsabilidades.

En lo que refiere a los cargos públicos, Bernardo (1993) sostiene que se trata de un medio muy importante para la política del bien común. El mérito de la virtud y el talento es el primer postulado para una política de cargos públicos, y todos los demás títulos y cualidades que puedan exhibirse solo son válidos en función de aquellos. La moralidad en los cargos públicos constituye la mejor garantía en la realización del bien común. Por tanto, deben ser llamados a gobernar aquellos a quienes se les reconozca idoneidad y se les compruebe experiencia en el manejo de los negocios públicos.

Debe, asimismo, puntualizarse que los modelos sociales y económicos no son neutrales y ajenos a los valores en lo más mínimo. De hecho, las políticas públicas deben orientarse a la consecución de fines de justicia y equidad. Sin embargo, ¿cómo podría esperarse que se diese lo que no se tiene? No puede haber justicia, misericordia y solidaridad en los corazones de hombres y mujeres que no han conocido el Evangelio que lo inspira. Cuando el corazón abriga violencia, maldad y opresión, evidentemente las mayorías sufren (Proverbios, 29: 2). 


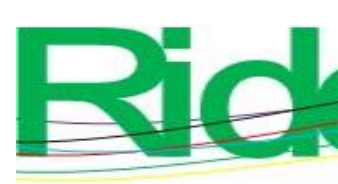

Revista Iberoamericana para la Investigación y el Desarrollo Educativo ISSN $2007-7467$

Los valores, el derecho y la propia ley de la conciencia colocan fronteras a nuestra conducta. Cuando traspasamos los límites nos lesionamos todos, pues el egoísmo ilimitado nos enfrenta y divide permanentemente. De esto último hay un sinfín de señales no solo en el orden internacional, sino también en el ámbito de la vida familiar. Si no se privilegia la justicia, tampoco se puede alcanzar el desarrollo. La buena conciencia, el derecho y la conducta ética traen salud y bienestar a quienes se empeñan en ello.

\section{Conclusiones}

En este trabajo se ha destacado el papel de los valores éticos y los retos del desarrollo económico. Los valores son fundamentales para evitar que el flagelo de la corrupción derrumbe la confianza tanto propia como de los extranjeros, quienes deciden invertir para generar las diversas virtudes del desarrollo económico y social, aun cuando ello implique asumir ciertos niveles de riesgo. Adicionalmente, bien puede señalarse que la ética se asocia a la existencia de ganancias derivadas de un juego económico justo, favorecedor de la sana competencia y respetuoso de los consumidores y demás agentes económicos.

En lo que respecta al análisis crítico sobre los contenidos seleccionados de la LE, debe puntualizarse que, en general, los planes de estudio de las IES tienden a confluir en cuanto a misión, visión, valores, contenidos, objetivos y otros aspectos. No obstante, sin dejar de lado lo cognoscitivo, debe enfatizarse en los valores para el desarrollo social y económico, con una perspectiva realista de los hechos.

Como en todos los valores, los educacionales tienen una contribución en la formación para la vida profesional. Se espera, por tanto, que los programas de valores de las IES no sean letra muerta o un catálogo de buenas intenciones. Se reconoce su necesidad cuando se observa cómo la sociedad se ve perjudicada frente al ascenso de las actividades delictivas, de corrupción política, de prácticas depredadoras de algunos empresarios, así como de la cultura de la ilegalidad ciudadana. La competencia desleal, el individualismo y la formación propia de la "ley de la selva" derivan en la desunión social y fractura las relaciones de familia. La educación de los valores debe no solo interesar al individuo en los aspectos de aprendizaje de contenidos, sino también estimularlo a promover soluciones de problemas concretos.

Los programas de valores que están desarrollando las IES, tanto en la integración del currículo como en su código de ética, se justifican a partir del reconocimiento de la crisis de valores que afecta a la comunidad internacional. Es evidente que estos programas de 


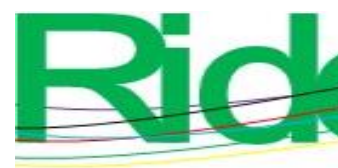

Revista Iberoamericana para la
Investigación y el Desarrollo Educativo
ISSN $2007-7467$

formación de valores por sí mismos no son suficientes para concientizar al estudiante acerca de su conducta ética y su eventual desarrollo profesional. Se requiere, por tanto, de las tareas complementarias de educación de las iglesias, la formación en familia, de los medios de comunicación y demás organismos de la sociedad civil.

En los diferentes ámbitos en que participa la ciencia económica debe estar al servicio de la sociedad en su conjunto. Existen beneficios intrínsecos en sus principios y su campo de aplicación. También deben reconocerse sus limitaciones, las cuales reflejan la esencia imperfecta, compleja y de intereses creados de los agentes sociales, políticos y económicos. Como profesional, el economista tendrá una visión sesgada de su contribución cuando solo beneficie a una minoría, a expensas del grueso de la sociedad. Los fracasos económicos serán también los fracasos en la ética, por lo que no se podrá alcanzar su razón de ser. El profesional de la economía y de campos similares deben tener muy clara la misión a la cual no deben renunciar.

Finalmente, deben señalarse que la temática aquí abordada debiera inspirar futuras líneas de investigación en México, pues en las misma se vinculan los valores éticos con la agenda del desarrollo social y económico, de modo tal que no solo se pretenda privilegiar los abordajes predominantemente utilitaristas de la Ciencia económica y demás disciplinas. Los valores éticos seguirán siendo relevantes, pues asi lo atestiguan aquellas comunidades y naciones que los cultivan y que asimismo revelan importantes progresos en los diversos campos que tiene el desarrollo en un contexto de libertad por las personas y respeto por las instituciones creadas para nuestro bienestar. 


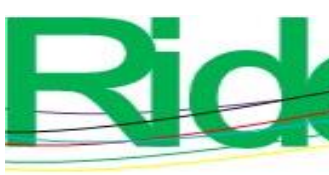

Revista Iberoamericana para la Investigación y el Desarrollo Educativo ISSN 2007-7467

\section{Referencias}

Acemoğlu, D. y Robinson, J. (2012). Por qué fracasan los países. Los orígenes del poder, la prosperidad y la pobreza. Ciudad de México: Crítica.

Altmann, W. (2002). Los desafíos éticos y el desarrollo. Una perspectiva teológica protestante. En Kliksberg, B. (comp.), Ética y desarrollo: la relación marginada. Buenos Aires: El Ateneo.

Bernardo, J. D. (1993). Ética de los negocios. Buenos Aires: Machi Grupo Editorial.

Brant, J. (2011). The case for values in economics education. Citizenship, Social and Economics Education, 10(2).

Diccionario Word Reference (2020). Ética. Recuperado de https://www.wordreference.com/sinonimos/\%C3\%A9tica

Florencio Contreras, A. (2009). Crisis económica y crisis de valores. En Universitarios Potosinos (pp. 30-33). Recuperado de https://ninive.uaslp.mx/xmlui/bitstream/handle/i/2669/04_200903.pdf?sequence=2 \&isAllowed=y

Kliksberg, B. (2006). La ética importa. Revista Venezolana de Gerencia, 8(24). Recuperado de https://www.produccioncientificaluz.org/index.php/rvg/article/view/9708/9694

Latapí, P. (1999). Valores: la asignatura pendiente. Proceso, 30.

Leibowitz, Y. (1995). Judaism. Human Values and the Jewish State. Cambridge, Massachusetts: Harvard University Press.

Martínez Navarro, I. (2017). Ética del desarrollo en un mundo globalizado. Veritas, 37. Recuperado de https://scielo.conicyt.cl/scielo.php?script=sci_arttext\&pid=S071892732017000200035

Ortega y Gasset, J. (1973). An Interpretation of universal history. Massachusetts: Norton and Company Incorporated.

Programa de Naciones Unidas para el Desarrollo (2019). Índice de desarrollo humano. Recuperado de http://report.hdr.undp.org/es/

Racko, G. (2017). The Values of economics. Journal of Business Ethics, 154, 35-48. Retrieved from https://link.springer.com/article/10.1007/s10551-017-3442-5

Ramos Sánchez, J. (2010). México en una era de decadencia social. México: Instituto Politécnico Nacional. 


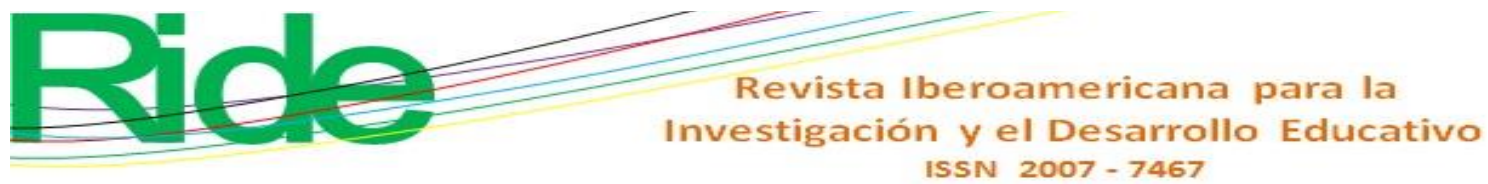

Real Academia Española (2020). Diccionario de la lengua española. Madrid: Ética. Recuperado de https://dle.rae.es/\%C3\%A9tico

Sen, A. (1999). Desarrollo como libertad. New York: Oxford University Press.

Tozer, A. W. (2013). La búsqueda de Dios por el hombre. Florida: Casa Creación.

Universidad Autónoma de Tamaulipas (2016). Plan de estudios de la licenciatura en Economía. 